\title{
OPTIMIZATION OF PRODUCTIVITY WITH SURFACE MINER USING CONVEYOR LOADING AND TRUCK DISPATCH SYSTEM
}

\author{
S. K. Palei ${ }^{1}$, N. C. Karmakar ${ }^{2}$, P. Paliwal ${ }^{3}$, B. Schimm ${ }^{4}$ \\ ${ }^{1}$ Assistant Professor, ${ }^{2}$ Professor, Department of Mining Engineering, Indian Institute of Technology (Banaras Hindu \\ University), Varanasi 221005, U.P., India, skpalei.min@iitbhu.ac.in \\ ${ }^{3}$ Assistant Manager, Chhatarpur I Mine, Pathkhera Area, WCL, Coal India Limited \\ ${ }^{4}$ Manager, Mining Division, Wirtgen GmbH, Windhagen, Germany
}

\begin{abstract}
This paper aims at optimizing the productivity at the surface miner's face with conveyor loading and dump-truck dispatch system to minimize the down times of surface miner as well as trucks. The surface miner was working in opencut method in a limestone mine located in the Southern part of India. Time study was carried out during three working shifts (each of eight-hour duration) for productivity analysis. A model has been developed and simulated in MATLAB for the productivity of surface miner considering the impact of two major parameters - number of trucks and available face length. The number of trucks for optimum production was found to be five. However, the 5\% and 95\% confidence interval for the number of trucks was 2.3 and 7.4 respectively for the case study face. It was also observed that the face of $330 \mathrm{~m}$ length was sufficient for the surface miner to work efficiently.
\end{abstract}

Index Terms: Opencast mine, Surface miner, Mining machinery, Truck dispatch system, Productivity analysis

\section{INTRODUCTION}

Surface miner is a crawler mounted machine generally used for selective mining of coal and useful minerals. Though the first surface miner was introduced to the South African gypsum mine in 1983, now-a-days about 300 machines are working worldwide. The application of rock cutting technology has been extended with the mechanization process to increase the productivity of mines. Surface miners play an important role in getting the desired production in opencast mines. The site-specific problems still exist in some of the mines to get the desired output from the opencast mines.

The present work is based on time-study data collected for a surface miner with conveyor loading and dump-truck (henceforth called truck) dispatch system in a limestone mine. The major parameters influencing the productivity of the surface miner are strength of rock mass, area available for mining operation, availability of trucks and their capacity, cutting tools used, and production planning. Mining industry emphasizes on the best possible utilization of its resources to increase the productivity. This paper aims at optimizing two important parameters like face length and availability of dump-trucks through a developed simulation model to increase the productivity of the mine.

\section{BACKGROUND}

It is the requirement of mining industry to produce good quality minerals with the available techniques. Surface miners are generally deployed for selective mining of minerals for efficient exploitation of the deposit. It eliminates the multiple operations such as drilling, blasting and primary crushing. Surface miner drastically reduces whole body vibration of operator. There are also environmental gains in terms of noise levels and air-borne dust concentrations [1]. The surface miners are used in opencast mines for mining the soft sedimentary deposits layer by layer, and dispatching the mined out material onto the truck traveling alongside, or side-casting, or windrowing the material [2]. The mineral is cut into small lumps/chips and can be transported through in-built conveyor belts [3]. It works on the principle of the central drum cutting technology. The cutting drum has cutting tool holders welded to its body in the form of helix. Cutting tool holders are specially designed, replaceable, and picks are fitted to these tool holders. The drum is driven mechanically by a diesel engine of adequate power by a shifting clutch and power belts acting on the drum gear. The first surface miner was deployed in the Indian mineral sector in 1994 to a limestone mine of Gujarat Ambuja Cements Limited, Gujarat [3]. Since then Wirtgen surface miners have gained popularity in India for mining soft to medium hard limestone and coal deposits. Currently, in various mining companies, multiple units of surface miners are in operation e.g., Gujurat Ambuja (7 unit), Madras Cements (5 units), India Cement (3 units) and MPL (2 units) [4]. Surface miners have already proved their strength as a profitable alternative to conventional mining methods. The use of surface miner is also an alternative, where blasting is prohibited or use of explosives is a crucial issue. 


\section{METHODOLOGY}

The time study was carried out to increase the productivity of the surface miner with conveyor loading and truck dispatch system. A model has been developed to minimize the idle time of surface miner and trucks, and to estimate the optimum face length desired for a surface miner to work effectively.

\subsection{Mine Description and Data Collection}

The opencast limestone mine is located in the Southern part of India, where the surface miner was working in the opencut method (as shown in Fig. 1) during time study. Opencut is a method in which surface miner cuts the material along the face-length and returns to the starting place simultaneously cutting the adjacent slice [3]. Time-study was carried out for three shifts, consisting of two II Shifts (working hours between 2 p.m. to 10 p.m.) and one III Shift (working hours between 10 p.m. to 6 a.m.). The changes in engine 'hourly machine rate' (HMR) for each eight-hour shift were 5.1, 6.3 and 5.2 hours respectively. The surface miner, SM 2200 (Wirtgen make), was working at the same face for all the shifts during the time study. The SM 2200 used had a maximum cutting depth of $300 \mathrm{~mm}$ with cutting width of $2200 \mathrm{~mm}$. The surface miner was working in a face of length about $330 \mathrm{~m}$ and width $50 \mathrm{~m}$. The average production rate was 288.3 tonnes per hour from the case study face. The mean capacity of the trucks used during the study period was 23.3 tonnes with variance of 2.4 .

\begin{tabular}{l|l|l|l|l|l|l|l|l|l|}
\hline 10 \\
\hline 1 & 2 & 3 & 4 & 5 & 6 & 7 & 8 & \\
\hline & 9 & 10 & 11 & 12 & 13 & 14 & 15 & 16 & \\
\hline & 17 & 18 & 19 & 20 & 21 & 22 & 23 & 24 \\
\hline \\
\hline
\end{tabular}

Fig1. Cutting sequence of a Surface Miner in Opencut method (Source: Wirtgen Surface Mining manual, 2002).

\subsection{Development of Simulation Model}

The independent variables are loading time of trucks, the cutting time of surface miner to load a truck, truck positioning time, truck hauling time, truck waiting time at the face, and the cycle time of a truck. The response variables were the number of trucks and length of the face. The schematic diagram of the conveyor loading-truck dispatch system is depicted in Fig. 2.

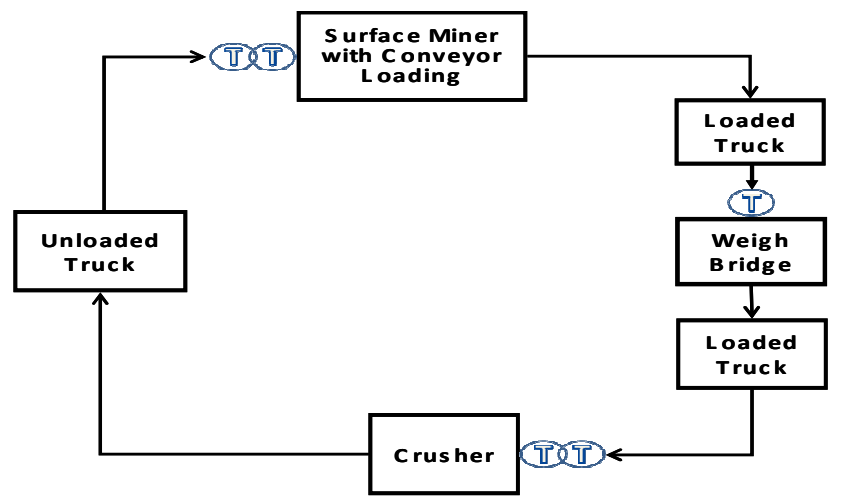

Fig2. Schematic diagram of Surface miner's conveyor loading and truck dispatch system

The following notations have been used:

$\mathrm{C}_{\mathrm{s}}$ : Cycle time of the SM

$\mathrm{C}_{\mathrm{t}}$ : Cutting time of SM to load a truck

$\mathrm{S}_{\mathrm{t}}$ : Positioning time of SM in opencut method of working after turning

$\mathrm{I}_{\mathrm{s}}$ : Idle time i.e. down-time of SM

$\mathrm{T}_{\mathrm{t}}$ : Turning time of SM

$A_{c}$ : Actual cutting time of SM in a single cycle

$\mathrm{C}_{\mathrm{d}}$ : Cycle time of truck

$\mathrm{H}_{\mathrm{d}}$ : Hauling time of trucks

$\mathrm{U}_{1}$ : Unloading time of trucks

$\mathrm{T}_{\mathrm{w}}$ : Truck waiting time in the queue at the face

$\mathrm{T}_{\mathrm{s}}$ : Truck positioning time

$\mathrm{L}_{\mathrm{d}}$ : Loading time of truck $=\mathrm{C}_{\mathrm{t}}+\mathrm{T}_{\mathrm{s}}$

$\mathrm{Ac}^{\prime}$ : Average cutting time of a surface miner to load a single truck

$\mathrm{N}_{\mathrm{d}}$ : Number of trucks required in a single cycle of SM

The cycle time of surface miner $\left(\mathrm{C}_{\mathrm{s}}\right)$ and that of the truck $\left(\mathrm{C}_{\mathrm{d}}\right)$ are obtained from the following relationships:

$\mathrm{C}_{\mathrm{d}}=\mathrm{C}_{\mathrm{t}}+\mathrm{T}_{\mathrm{s}}+\mathrm{H}_{\mathrm{d}}+\mathrm{U}_{1}+\mathrm{T}_{\mathrm{w}}$

$\mathrm{C}_{\mathrm{s}}=\mathrm{C}_{\mathrm{t}}+\mathrm{T}_{\mathrm{s}}+\mathrm{S}_{\mathrm{t}}+\mathrm{T}_{\mathrm{t}}+\mathrm{I}_{\mathrm{s}}$

The number of trucks $(\mathrm{N})$ can be related to the time parameters for developing the model. The number of trucks for efficient exploitation of the deposit for increasing the productivity of the surface miner face can be calculated as outlined below:

Average cutting time to load a truck

$$
\mathrm{Ac}^{\prime}=\frac{\text { Cycle time of SM }}{\text { Number of trucks in single cycle of SM }}
$$

No. of trucks required in a single cycle of SM

$\mathrm{N}_{\mathrm{d}}=\frac{\text { Actual cutting time of SM in a cycle }}{\text { Loading time of a truck }}$ 
Total no. of trucks required for the SM face $(\mathrm{N})$

$$
\begin{gathered}
=\frac{\text { Cycle time of a truck } \times \text { Actual cutting time of } \mathrm{SM} \text { in a single cycle }}{\text { Cycle time of } \mathrm{SM} \times \text { Loading time of a single truck }} \\
=\frac{\mathrm{C}_{\mathrm{d}} \times \mathrm{A}_{\mathrm{c}}}{\mathrm{C}_{\mathrm{s}} \times \mathrm{L}_{\mathrm{d}}} \\
=\frac{\left(\mathrm{C}_{t}+\mathrm{H}_{d}+\mathrm{U}_{l}+\mathrm{T}_{w}+\mathrm{T}_{s}\right) \times \mathrm{A}_{c}}{\left(\mathrm{C}_{t}+\mathrm{T}_{s}+\mathrm{T}_{t}+\mathrm{S}_{t}+\mathrm{I}_{s}\right) \times\left(\mathrm{T}_{s}+\mathrm{C}_{t}\right)}
\end{gathered}
$$

Actual cutting time of surface miner in a cycle is the time during which a surface miner cuts and loads the material onto the trucks. It is the cycle time of surface miner excluding idle time, turning time and truck waiting time. The collected data are processed to fit to the suitable statistical distribution for simulation. The independent and response variables were modeled by fitting to suitable probability density functions. A model was developed to maximize the production simultaneously optimizing system utilization at the surface miner face to increase the overall work efficiency of the system.

\subsection{Modeling of Independent Variables}

The independent variables in this study are truck positioning time, cutting time of surface miner, hauling time of truck, truck waiting time, turning time of surface miner and idle time of surface miner. The modeling of independent variables from the collected time study data were fitted to suitable probability density functions. For fitting the data to probability distributions, SIMULINK of MATLAB 7.0.1 was used [5]. The observed data as well as the fitted curves are depicted in Fig. 3 for the independent variables.

Before surface miner starts cutting and simultaneously loading onto the truck, the truck should be positioned properly so that spillage of material is minimum. This time is called the truck positioning time (Ts in min). This truck positioning time is fitted to a single parameter exponential distribution with $\beta=$ $0.17 \mathrm{~min}$ as shown in Fig. 3(a). Hauling time of truck (Hd) is the time taken by truck from the face to the unloading point (may be dump yard or crusher) and coming back to the face, excluding time of loading and truck waiting time for loading.
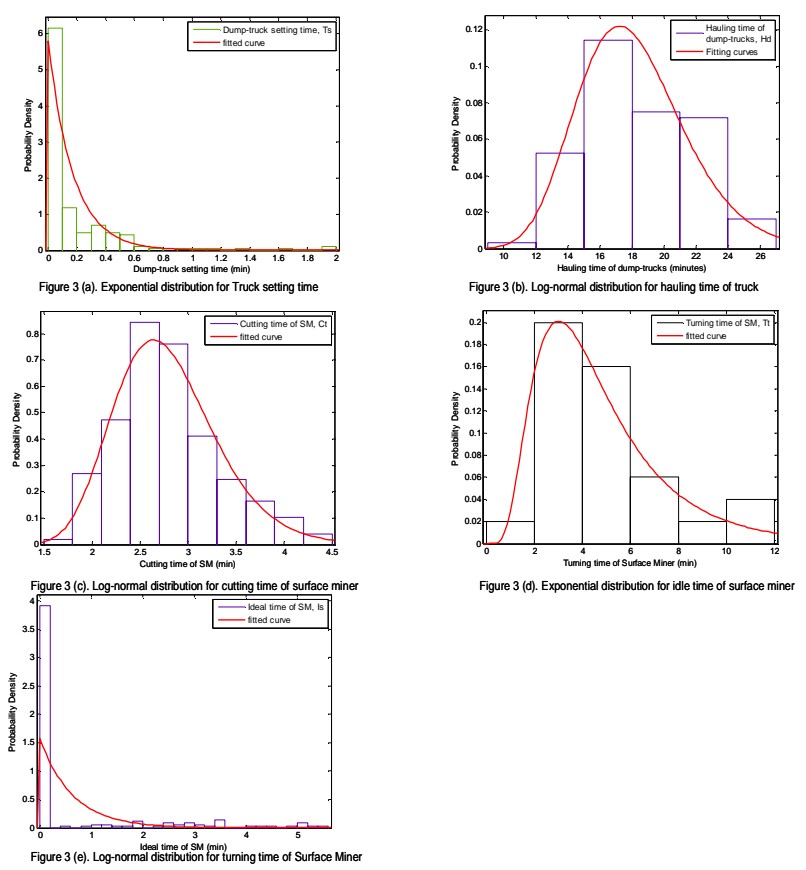

Fig3. Observed as well as fitted distributions of various time variables

The observed as well as fitted curves for hauling time of trucks (Hd, in min) is presented in Fig. 3(b). The hauling time is fitted to a log-normal distribution with $\mu=2.88$ and $\sigma=0.19$. Cutting time of surface miner to load a truck $(\mathrm{Ct})$ is time taken by a surface miner to cut the mineral and load a single truck. The observed as well as fitted curves for cutting time of surface miner to load a single truck $(\mathrm{Ct})$ are presented in Fig. 3 (c). The cutting time of surface miner to load a single truck is fitted to a log-normal distribution with $\mu=1.01$ and $\sigma=0.19$. Down time of surface miner (Is) is the time during which the surface miner was not cutting and loading. The observed as well as the fitted curves for down time of surface miner (Is) is presented in Fig. 3(d). The data is fitted to an exponential distribution with mean value of $0.63 \mathrm{~min}$. Turning time $(\mathrm{Tt})$ is the time taken by the surface miner to take a turn and enter in another line of cutting and loading. The turning time of surface miner is fitted to a log-normal distribution with parameters $\mu=1.42$ and $\sigma=0.56$ as depicted in Fig. 3(e).

\section{ANALYSIS AND RESULTS}

Random samples are selected for the response variable, number of trucks and length of face based on the modeled independent parameters. The developed model was simulated with a program written in MATLAB. The number of trucks was estimated in surface miner face to optimize the conveyor loading-truck dispatch system by collecting 10,000 samples. The mean number of trucks required was found to be 4.7 with standard deviation of 1.2 (as shown in Fig. 4). Hence, the number of trucks based on the results of simulation model 
would be 5 (taking integer approximation of 4.7). However, the $5 \%$ and $95 \%$ confidence interval for the number of trucks was found to be 2.3 and 7.4 respectively. The effect of face length on productivity of surface miner was estimated from the available time study data as shown in Fig. 5. It demonstrates that with increase in face length, say up to $330 \mathrm{~m}$, the hourly production of surface miner increases, beyond which there's only marginal improvement in productivity.

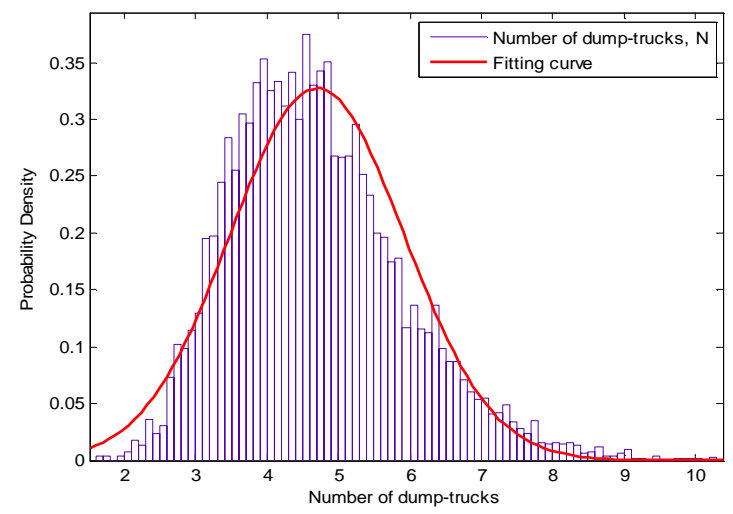

Fig4. Simulation results for number of dump-trucks

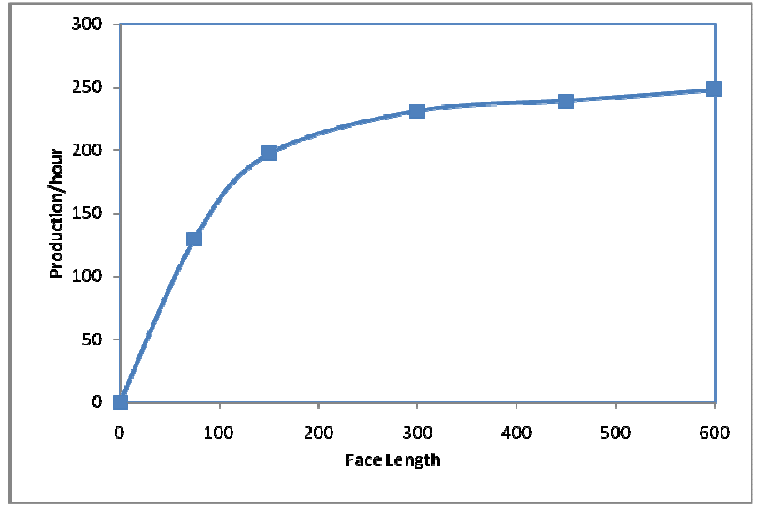

Fig5. Hourly productivity of SM vs. face length

\section{CONCLUSIONS}

This paper explains how to optimize the production in a surface miner face with conveyor loading to minimize idle time of both surface miner and trucks. Two parameters namely, face length and the availability of number of trucks at the surface miner face are considered for the study. The idle times (such as unavailability of trucks, turning and repositioning of surface miner, jamming of material in conveyor belt and its clearance, break for operator change), and truck positioning are always associated with the surface miner. A simulation model was developed and the time study data of a limestone mine was used to optimize the area availability and to assign desired number of trucks. The surface miner was working in opencut method with direct conveyor directly loading onto trucks. The number of trucks and area availability (e.g., face length) has been estimated to efficiently increase the productivity of the system. The parameters of the time study data were modeled to suitable 'probability density functions' by SIMULINK of MATLAB 7.0.1 and a program was written to simulate the developed model. The number of trucks based on the simulation results would be five. The mean truck capacity used during the time study was 23.3 tonnes with the variance of 2.4 . It is also observed $330 \mathrm{~m}$ face length was optimum from productivity pointy of view.

The objective of this paper was to optimize the idle time of both surface miner and trucks to increase work efficiency and productivity. During modeling of idle time of surface miner, major breaks continuing for more than 20 min were excluded for the sake of simplicity in calculation. This study can be extended to consider the cutting speed of surface miner and hauling speed of surface miner to estimate the number of trucks for efficient operation. Any change in truck capacity, face length, surface miner's model, make and productivity, and rock characteristics may affect the results of the developed model. The developed methodology can well be extended to other mines having similar conveyor loading-truck dispatch arrangement.

\section{ACKNOWLEDGEMENTS}

The authors are grateful to Wirtgen India Private Limited, Bangalore for their permission to use the time-study data. The authors are also grateful to the mine management for their cooperation.

\section{REFERENCES}

[1] . Dey, K and Bhattacharya, J.: Operation of Surface Miner: Retrospect of a Decade Journey in India. Procedia Engineering, 2012, Vol. 46, pp. 97 - 104.

[2]. B. Schimm: Economic mining of thin seams in flat deposits with surface miners, Mining Technology, 1996, 78(895), pp.89-92.

[3]. Wirtgen surface mining manual, Wirtgen group, Windhagen, Germany, p.52, 2002.

[4] . Prakash, A., Murthy, V. M. S. R. and Singh, K. B.: Rock excavation using surface miners: An overview of some design and operational aspects. International Journal of Mining Science and Technology 2013, Vol. 23, pp. 33-40.

[5]. MATLAB 7.0.1: Matlab software package. 